\title{
Comparison of Dementia Awareness among Medical Technicians: Physiotherapists and Occupational Therapists
}

\author{
Ae-Lyeong Kwon', Ki-Jeon Kim² \\ 'Department of Special Education (Physics, Occupational Therapy), Graduate of General, Dankook University, Yongin, Republic of Korea; \\ ${ }^{2}$ Department of Rehabilitation and Health, Graduate School of Health Science, Hallym University, Chuncheon, Republic of Korea
}

Purpose: The aim of this study was to compare dementia awareness among physiotherapists and occupational therapists who treat dementia patients and provide opportunities to increase dementia awareness as medical technicians, expand the scope of treatment, and enhance professionalism.

Methods: An online survey was conducted from January 8th to 19th, 2021 for physical therapists who are members of the Korean Physical Therapist Association and Occupational therapists who are members of the Korean Occupational Therapists Association. The collected data were analyzed using the SPSS 21.0 program. To verify the difference in the awareness of dementia among medical technicians, a ttest was performed, and the chi-square test was used to analyze the difference in the responses for each question.

Results: In this study, occupational therapists had a significantly higher average and standard deviation than physical therapists. Occupational therapists also had a significantly higher level of dementia awareness, including dementia symptom-related, dementia diseaserelated, and dementia therapy knowledge.

Conclusion: The results of this study indicate that various educational initiatives and systems should be developed to help medical professionals increase their awareness and interest on dementia as a community, which can enable them to move in the same treatment direction with a common goal.

Keywords: Medical technician, Physical therapist, Occupational therapist, Dementia, Awareness

\section{서 론}

우리나라는 과학의 발전으로 인해 의료 수준이 높아지고 있고, 그 로 인해 평균 수명이 연장되고 있으며 빠르게 초고령화가 진행되고 있다. 2021 년 현재 고령화 비율은 $16.7 \%$ 로 높아졌으며 비율은 점차 증 가추세로 2030 년에는 $25.0 \%, 2040$ 년에는 $33.9 \%$ 로 증가할 전망이다. ${ }^{2}$ 이렇듯 초고령사회로 진행되면서 만성질환을 가진 노인 인구도 증가 되는 것을 알 수 있다. 2021 년 치매유병현황에 의하면 만성질환 중 하 나인 치매를 않고 있는 65 세 이상의 노인수가 전국적으로 $10.3 \%$ 로 증 가가 계속되고 있다. ${ }^{4}$

치매는 기억장애와 더불어 언어장애, 시공간장애, 집행기능 장애 중 적어도 한 가지 이상의 장애를 보이는 임상증후군이며, 노인이 가 장 두려워하는 병으로 나이가 많을수록 발병 가능성이 증가되는 만 성퇴행성 질병이다.5, 치매를 일으키는 질환은 점점 더 많이 밝혀지
고 있지만, 이러한 질환들이 진전되는지에 대해서는 알려진 바가 없 으며, 가장 흔한 형태의 치매는 알츠하이머병(alzheimer ' fisease)과, 혈 관성 치매(vascular dementia), 루이소체 치매(luwy body dementia), 전. 측두엽성 치매( Frontotemporal dementia)이다. 치매는 다양한 원인으 로 인해 뇌기능이 손상되어 지적, 인지적 기능이 지속적으로 저하되 면서 식사하기와 옷 갈아입기, 대소변 가리기 등 혼자서 할 수 있는 일상생활 수행능력에 장애가 나타난다. 치매로 인해 신체 중 가장 현 저하게 변화되는 것은 근육 및 골격계의 변화로 이는 치매 환자의 활 동에 직접적인 영향을 주며 매우 심각한 기능적 문제를 일으킨다. ${ }^{9}$ 이 러한 대부분의 치매는 비가역적이며, 명확한 원인이 밝혀져 있지 않 아서, 원인적 치료가 매우 어렵기 때문에 종합적 치료 접근이 필요하 다. ${ }^{10}$ 치매 치료에는 기본적으로 약물치료를 하며, 인지적 활동과 신 체적 활동 치료를 함께 하는데, 이러한 치료를 담당하는 의료기사는 물리치료사와작업치료사이다.11 
의료기사는 의사 또는 치과의사의 지도 아래 진료나 의화학적 검 사에 종사하는 사람을 말하며, 물리치료사와 작업치료사, 임상병리 사와 방사선사, 치과기공사 및 치과위생사가 있다. ${ }^{12}$ 이 중 직접적으로 환자를 치료하는 의료기사는 신체의 교정 및 재활을 돕는 물리치료 사와 신체적. 정신적 기능장애를 회복시키는 작업치료사다. ${ }^{13}$ 물리치 료사와 작업치료사는 병원이나 요양시설, 치매센터 등에서 치매 환 자를 위해 전문가로서의 역할을 수행하고 있다. ${ }^{4}$ 물리치료사는 치매 환자의 인지장애와 행동학적 문제들을 감소시키기 위해 일상생활 수행능력(Activity of Daily Living, $\mathrm{ADL}$ )을 이용하여 목욕하기와 옷갈 아입기, 화장실 이용과 식사하기, 이동하기 등을 할 수 있도록 재활 훈련을 시킨다. ${ }^{15}$ 작업치료사는 일상생활에서 흔히 사용되는 물건이 나 기구를 활용하여 감각활동 훈련과 작업적 일상생활 훈련, 인지재 활 훈련 등 재활치료를 한다. ${ }^{16}$ 이러한 치매를 치료하는 물리치료사나 작업치료사가 치매에 대한 인식을 제대로 하지 못한 채 치료를 하게 되면 치매 진단과 조기 발견이 늦어지게 되고, 이로 인해 적절한 대응 과 치료가 이루어지지 않을 수 있다..$^{17}$

의료기사들은 치매에 관한 여러 가지 문제에 대해 도움을 받거나 해결하기 위해 각각의 협회나 치매를 전문으로 교육하는 협회에서 교육을 받는다. 매년 국민건강보험공단에서도 '치매전문교육'을 실시 하는데 교육과정에는 치매에 대한 인식과 태도에 대한 내용은 배제 되어 있으며, 치매 교육은 치매 환자의 인지훈련 활동에 편중되어 있 거나 실무 중심으로 진행되고 있어서, 올바른 치매 인식과 태도를 갖 고 있지 않은 치료사라면 부정적인 편견을 갖고 치매 환자를 치료할 수도 있을 것이다. ${ }^{18}$ 치매 환자에게 있어 가장 중요한 도움은 일상생 활을 할 수 있게 하는 것이다. ${ }^{14}$ 다양한 수준의 신체 활동은 인지 장애 와 신체 기능을 향상시키며 불안한 행동과 불안정성을 개선시킬 수 있다. ${ }^{19,20}$ 그렇기 때문에 의료기사로서 치매 환자의 조력자로서, 치매 에 대한 인식을 바르게 이해하고, 부정적인 인식을 개선시켜 나가며, 치매 환자의 잔존 능력을 유지시켜야 한다. ${ }^{21}$

치매 인식에 관한 연구는 다양하지만 많지는 않다. $\mathrm{Kim}$ 과 $\mathrm{Cho}^{17}$ 는 물리치료학과 학생들을 대상으로 치매 인식도 조사를 하였고, Kim 과 Jung ${ }^{3}$ 은 거주지에 따른 지역주민의 치매 인식도 비교를 하였다. 또 한 서울시와 그 외 지자체 등에서도 인식도 조사를 하였지만 의료기 사를 대상으로 한 연구는 없었다. ${ }^{1}$ 따라서 본 연구는 치매 환자를 직 접 임상에서 치료하는 물리치료사와 작업치료사의 치매 인식도를 비교하여 알아보고, 의료기사로서 치매의 인식도를 높일 수 있는 계 기를 마련하고자 한다. 또한 전문가로서 치료 분야의 영역을 넓히고 전문성을 높여 서비스 질을 향상시키는데 도움이 되는 방향을 모색 하고자한다.

\section{연구 방법}

\section{1. 연구 대상 및 기간}

본 연구의 참여자는 대한 물리치료사 협회 회원인 물리치료사와 대한 작업치료사 협회 회원인 작업치료사에게 치매 인식도에 관한 설문 조사를 하였다. 2021년 1월 8일부터 19일까지 온라인 설문지를 통하여 조사를 하였다. 표본수 선정은 G-power을 사용하여 effect size d: 0.5/a err prob: 0.05 /power (1- $\beta$ err prob): 0.8 로 하였다(Table 1).

\section{2. 자료 수집}

설문 조사는 총 121 명이 참여하였으며, 그 중 중복된 설문 1 부와 답 이 누락된 4 부를 제외한 116 부를 조사하였다. 연구조사는 익명으로 하였으며, 설문 참여에 관한 동의를 구하였다. 연구 진행에 필요한 설 문 이외의 개인 정보는 수집하지 않았다. 설문 내용은 의료기사(물리, 작업치료사)의 치매 인식도 비교 조사로 의료기사들의 일반적 특성 과 치매 관심도이며, 치매 인식도는 3 부분으로 나누어 조사하였다. 모든 문항은 33 문항이며, 1 인당 설문지 작성 소요시간은 5-10분 정도 소요되었다.

\section{3. 측정 도구 및 방법}

1) 연구 도구

본 연구에서 사용된 치매 인식도는 $\mathrm{Kim}$ 과 $\mathrm{Cho}^{17}$ 의 물리치료학과 학생들의 치매 인식도 조사연구와 $\mathrm{Kim}^{22}$ 의 제주시민의 치매에 대한 인식과 태도에 관한 연구에서 사용한 설문지를 수정하여 사용하였 다. 설문조사에서 사용된 설문 문항은 총 20 문항으로 치매 증상에 관한 지식이 5 문항, 질병에 관한 지식이 5 문항, 치료에 관한 지식이 10 문항이다. Kwon ${ }^{14}$ 의 연구에서 치매 인식도에 관한 신뢰도는 Cronbach's $\alpha=0.79$ 으로 나왔으며, $\mathrm{Kim}^{22}$ 의 연구에서도 Cronbach's $\alpha=0.74$ 로 나왔다. 또한 Kim과 Jung ${ }^{3}$ 연구에서 Cronbach's $\alpha=0.738$ 로 나왔다. 본 연구에서도 치매 인식도에 관한 신뢰도는 Cronbach's $\alpha=0.748$ 로 나타났다.

\section{4. 자료 분석}

본 연구에서 수집된 자료를 분석하기 위해 SPSS 21.0 프로그램 (SPSS Inc., Chicago, IL, USA)을 사용하였다. 참여자의 일반적 특성을 알아보기 위해 빈도분석을 실시하였다. 본 연구에서 사용한 측정도 구들의 신뢰도를 확인하기 위하여 참여자들의 치매 인식도에 대해 신뢰도 분석을 실시한 후, Cronbach's a 계수를 산출하였다. 물리치료 사와 작업치료사 간의 치매 인식도 차이가 유의한 지 검증하기 위해 t검증을 실시하였으며, 유의 수준은 $\mathrm{p}<0.05$ 로 하였다. 물리치료사와 작업치료사의 문항별 응답에서 차이를 나타내는지를 알아보기 위해 
Table 1. Characteristics of participations

\begin{tabular}{|c|c|c|c|c|c|}
\hline & Total & Physical therapist N (\%) & Occupational therapist N (\%) & $\chi^{2}$ & $\mathrm{p}$ \\
\hline \multicolumn{6}{|l|}{ Sex } \\
\hline M & $38(32.8)$ & $32(84.2)$ & $6(15.8)$ & 19.267 & 0.001 \\
\hline $\mathrm{F}$ & $78(67.2)$ & $33(42.3)$ & $45(57.7)$ & & \\
\hline \multicolumn{6}{|l|}{ Age } \\
\hline $25-30$ & 39 (33.6) & $16(41.0)$ & $23(59.0)$ & & \\
\hline $31-40$ & $46(39.7)$ & $23(50.0)$ & $23(50.0)$ & 18.285 & 0.001 \\
\hline $41-50$ & $23(19.9)$ & $18(78.3)$ & $5(21.7)$ & & \\
\hline $51-60$ & $8(6.9)$ & $8(100)$ & $0(0)$ & & \\
\hline \multicolumn{6}{|l|}{ Final education } \\
\hline 3-year graduation & $38(32.8)$ & $26(68.4)$ & $12(31.6)$ & 15.734 & 0.002 \\
\hline 4-year graduation & $41(35.3)$ & 15 (36.6) & $26(63.4)$ & & \\
\hline Graduate Master's Degree & $24(20.7)$ & $13(54.2)$ & $11(45.8)$ & & \\
\hline Graduate Ph.D & $12(10.3)$ & $10(83.3)$ & $2(16.7)$ & & \\
\hline Etc. & $1(0.9)$ & $1(100)$ & $0(0)$ & & \\
\hline \multicolumn{6}{|l|}{ Occupational status } \\
\hline Have & $108(93.1)$ & $62(57.4)$ & $46(42.6)$ & 0.118 & 0.751 \\
\hline None & $8(6.9)$ & $3(37.5)$ & $5(62.5)$ & & \\
\hline \multicolumn{6}{|l|}{ Treatment target } \\
\hline Child & $55(47.4)$ & $22(40.0)$ & $33(60.0)$ & 26.581 & 0.001 \\
\hline Adult & 39 (33.6) & $29(74.4)$ & $10(26.4)$ & & \\
\hline Old man & $22(19.0)$ & $14(63.60$ & $8(36.4)$ & & \\
\hline \multicolumn{6}{|l|}{ Dementa treatment experience } \\
\hline Yes & $80(69.0)$ & $43(53.8)$ & $37(46.2)$ & 1.325 & 0.326 \\
\hline No & $36(31.0)$ & $22(61.1)$ & $14(38.9)$ & & \\
\hline \multicolumn{6}{|l|}{ Dementa treatment intention } \\
\hline Yes & $82(70.7)$ & $39(47.6)$ & $43(52.4)$ & 7.024 & 0.012 \\
\hline No & $34(29.3)$ & $26(76.5)$ & $8(23.5)$ & & \\
\hline \multicolumn{6}{|l|}{ Awarness of dementia } \\
\hline Know very well & $20(17.2)$ & $12(60.0)$ & $8(40.0)$ & 2.497 & 0.478 \\
\hline Know & $72(62.1)$ & $39(54.2)$ & $33(45.8)$ & & \\
\hline Average & $20(17.2)$ & $13(65.0)$ & $7(35.0)$ & & \\
\hline Do not know & $4(3.5)$ & $1(25.0)$ & $3(75.0)$ & & \\
\hline Have no idea & $0(0)$ & $0(0)$ & $0(0)$ & & \\
\hline \multicolumn{6}{|l|}{ Degree of interest in dementia } \\
\hline Know very well & $13(11.20$ & $8(61.5)$ & $5(38.5)$ & 7.259 & 0.049 \\
\hline Know & 44 (37.9) & $18(40.9)$ & $26(59.1)$ & & \\
\hline Average & $55(47.4)$ & 35 (63.6) & $20(36.4)$ & & \\
\hline Do not know & $4(3.5)$ & $4(100)$ & $0(0)$ & & \\
\hline Have no idea & $0(0)$ & $0(0)$ & $0(0)$ & & \\
\hline
\end{tabular}

카이제곱 검증을 통해 분석하였고, 마지막으로 Pearson 적률상관분 석을 실시하여 치매 인식도 간의 관계를 확인하였다. Pearson 적률 상 관관계는 두 변인 간의 상관관계를 수치로 나타내는 것이다. 정적 상 관관계는 0.0 보다 크고 1.0 과 같거나 작은 계수 값을 가지며, 부적 상 관관계는 -1.0 과 0.0 사이의 계수 값을 갖는다. 변인의 값이 증가함에 따라 다른 변인의 값이 증가하면 정적 상관관계, 변인의 값이 증가함 에 따라 변인의 값이 감소할 때 부적 상관관계라고 한다.

\section{연구 결과}

\section{1. 의료기사의 치매 인식도}

직업군을 물리치료사와 작업치료사로 구분한 후, 집단별 평균과 표준편차를 알아보기 위하여 독립집단 $\mathrm{t}$ 검증을 실시하였다. 치매 인 식도에서 집단 간 차이가 나타났으며 $(\mathrm{t}=-3.119, \mathrm{p}<0.01)$, 물리치료사 에 비해 작업치료사의 인식도가 유의하게 높은 것으로 나타났다. 인 
식도의 세부항목인 증상지식 $(\mathrm{t}=-2.971, \mathrm{p}<0.01)$ 과 질병지식 $(\mathrm{t}=-2.017$, $\mathrm{p}<0.05)$, 치료지식 $(\mathrm{t}=-2.176, \mathrm{p}<0.05)$ 모두에서 집단 간 차이가 나타났 으며, 물리치료사보다 작업치료사에서 세 항목 모두 평균이 유의하 게 높은 것으로 나타났다(Table 2).

\section{2. 의료기사의 치매 인식도 세부 영역 비교}

\section{1) 치매 증상 관련 지식}

집단 별 치매 증상 관련 지식에 대해 문항별로 카이제곱 검증을 수
행한 결과, '나이가 들면 노화에 의해 치매에 걸린다' '치매에 걸리면 가족과 생활하는 것이 불가능하다, '치매에 걸리면 이전에 비해 기억 력 등 인지 기능이 저하되어 일상생활에 지장을 초래하게 된다, '치매 에 걸리면 성격이 변할 수 있다에서 집단에 따른 유의한 차이가 나타 나지 않았다 $(\mathrm{p}>0.05)$. 그러나 '치매를 위해서는 환경을 자주 바꾸어 주면 도움이 된다'에서는 집단에 따른 유의한 차이가 나타났다 $(\mathrm{p}<$ 0.05)(Table 3).

Table 2. Mean and standard deviation of dementia awareness by group

\begin{tabular}{lccc}
\hline \multirow{2}{*}{ Variable } & Physical therapist $(n=65)$ & & Occupational therapist $(n=51)$ \\
\cline { 2 - 3 } & Mean \pm sd & Mean \pm sd & $-3.119^{* *}$ \\
Awareness & $3.67 \pm 0.34$ & $3.87 \pm 0.35$ & $-2.971^{* *}$ \\
Symptom knowledge & $3.57 \pm 0.42$ & $3.82 \pm 0.47$ & $-2.017^{*}$ \\
Disease knowledge & $3.48 \pm 0.52$ & $3.66 \pm 0.43$ & $-2.176^{*}$ \\
Therapy knowledge & $3.74 \pm 0.50$ & $3.94 \pm 0.50$ & \\
\hline
\end{tabular}

${ }^{*} p<0.05,{ }^{* *} p<0.01$

Table 3. Knowledge of symptoms of dementia

\begin{tabular}{|c|c|c|c|c|c|}
\hline & Total & $\begin{array}{l}\text { Physical therapist } \\
\qquad \mathrm{N}(\%)\end{array}$ & $\begin{array}{l}\text { Occupational } \\
\text { therapist N (\%) }\end{array}$ & $\chi^{2}$ & $\mathrm{p}$ \\
\hline \multicolumn{6}{|c|}{ Older age leads to dementia due to aging } \\
\hline Not at all & $3(2.6)$ & $2(3.1)$ & $1(2.0)$ & 3.465 & 0.487 \\
\hline Not like that & $40(34.5)$ & $19(29.2)$ & $21(41.2)$ & & \\
\hline So so & $25(21.6)$ & $13(20.0)$ & $12(23.5)$ & & \\
\hline Mostly & $47(40.5)$ & $30(46.2)$ & $17(33.3)$ & & \\
\hline It really & $1(0.9)$ & $1(1.5)$ & $0(0.0)$ & & \\
\hline \multicolumn{6}{|c|}{ Dementia makes it impossible to live with a family } \\
\hline Not at all & $12(10.3)$ & $6(9.2)$ & $6(11.8)$ & 4.466 & 0.326 \\
\hline Not like that & $53(45.7)$ & $26(40.0)$ & $27(52.9)$ & & \\
\hline So so & $22(19.0)$ & $16(24.6)$ & $6(11.8)$ & & \\
\hline Mostly & $28(24.1)$ & $16(24.6)$ & $12(23.5)$ & & \\
\hline It really & $1(0.9)$ & $1(1.5)$ & $0(0.0)$ & & \\
\hline \multicolumn{6}{|c|}{$\begin{array}{l}\text { If suffer from dementia, cognitive functions such as memory will } \\
\text { decrease compared to before, which will interfere with daily life. }\end{array}$} \\
\hline Not at all & $0(0.0)$ & $0(0.0)$ & $0(0.0)$ & 4.363 & 0.193 \\
\hline Not like that & $2(1.7)$ & $1(1.5)$ & $1(2.0)$ & & \\
\hline So so & $8(6.9)$ & $6(9.2)$ & $2(3.9)$ & & \\
\hline Mostly & $71(61.2)$ & $43(66.20)$ & $28(54.9)$ & & \\
\hline It really & $35(30.2)$ & $15(23.1)$ & $20(39.2)$ & & \\
\hline \multicolumn{6}{|c|}{ Dementia can change personality } \\
\hline Not at all & $0(0.0)$ & $0(0.0)$ & $0(0.0)$ & 3.058 & 0.388 \\
\hline Not like that & $3(2.60)$ & $3(4.6)$ & $0(0.0)$ & & \\
\hline So so & $18(15.50)$ & $8(12.3)$ & $10(19.6)$ & & \\
\hline Mostly & $64(55.2)$ & $37(56.9)$ & $27(52.9)$ & & \\
\hline It really & $31(26.7)$ & $17(26.2)$ & $14(27.5)$ & & \\
\hline \multicolumn{6}{|c|}{ It is helpful to change the environment frequently for dementia. } \\
\hline Not at all & $33(28.4)$ & $12(18.50)$ & $21(41.2)$ & 9.333 & 0.047 \\
\hline Not like that & $47(40.5)$ & $27(41.5)$ & $20(39.2)$ & & \\
\hline So so & $17(14.7)$ & $13(20.0)$ & $4(7.8)$ & & \\
\hline Mostly & $14(12.1)$ & $10(15.4)$ & $4(7.8)$ & & \\
\hline It really & $5(4.3)$ & $3(4.6)$ & $2(3.9)$ & & \\
\hline
\end{tabular}




\section{2) 치매 질병 관련 지식}

집단별 치매 질병 관련 지식에 대해 '치매는 병이다', '치매는 음주 나 약물과 관련이 있다, '치매는 유전적인 요인과 관련이 있다, '뇌졸 중 때문에 치매가 생길 수 있다'에서 집단에 따른 유의한 차이가 나타 나지 않았다 $(\mathrm{p}>0.05)$. 그러나 ‘남자가 여자보다 치매에 잘 걸린다’에서 는 문항에 따른 유의한차이가 나타났다 $(\mathrm{p}<0.05)($ Table 4$)$.

\section{3) 치매 치료 관련 지식}

집단별 치매 치료 관련지식에 대해 '치매는 조기 발견이 불가능하 다, '치료 가능한 치매도 있다', '치매 진단을 하기 위해 인지 기능검사 가 중요하다, '치매는 예방할 수 있는 방법이 없다', 물리치료나작업치 료로 치매의 진행을 늦출 수 있다'에서 집단에 따른 유의한 차이가 나타났다 $(\mathrm{p}<0.05)$. 그러나 규칙적으로 운동하면 치매 위험이 낮아진 다, '규칙적인 생활과 신체 정기 검사는 치매예방에 도움을 준다', '치
매는 약물치료가 도움이 된다', 싱겁게 먹고 균형에 맞는 식사는 치매 예방에 효과적이다, '혈압이나 혈당 조절이 치매 예방에 도움이 된다' 에서는 집단별 차이가 유의하게 나타나지 않았다( $\mathrm{p}>0.05)$ (Table 5).

\section{3. 치매 인식도에 관한 상관관계}

치매 인식도 간의 Pearson 상관계수를 구하였다. 인식도는 증상지 식 $(\mathrm{r}=0.473, \mathrm{p}<0.001)$ 과 질병지식 $(\mathrm{r}=0.631, \mathrm{p}<0.001)$ 치료지식 $(\mathrm{r}=0.878$, $\mathrm{p}<0.001)$ 모두와 유의한 정적 상관을 나타냈으며, 질병지식은 치료지 식과의 관계 $(\mathrm{r}=0.337, \mathrm{p}<0.001)$ 에서 정적 상관이 유의하였다(Table 6).

\section{고 찰}

본 연구는 설문 조사를 기반으로 의료기사인 물리치료사와 작업 치료사를 대상으로 치매에 관한 인식도를 비교하여 알아보았다. 먼

Table 4. Knowledge of dementia disease

\begin{tabular}{|c|c|c|c|c|c|}
\hline & Total & $\begin{array}{c}\text { Physical therapist } \\
\mathrm{N}(\%)\end{array}$ & $\begin{array}{l}\text { Occupational } \\
\text { therapist N (\%) }\end{array}$ & $\chi^{2}$ & $p$ \\
\hline \multicolumn{6}{|c|}{ Dementia is a disease } \\
\hline Not at all & $1(0.9)$ & $0(0.0)$ & $1(2.0)$ & 2.765 & 0.635 \\
\hline Not like that & $5(4.3)$ & $3(4.6)$ & $2(3.9)$ & & \\
\hline So so & $15(12.9)$ & $9(13.8)$ & $6(11.8)$ & & \\
\hline Mostly & $56(48.3)$ & $34(52.3)$ & $22(43.1)$ & & \\
\hline It really & 39 (33.6) & $19(29.2)$ & $20(39.2)$ & & \\
\hline \multicolumn{6}{|c|}{ Dementia is related to alcohol or drugs } \\
\hline Not at all & $1(0.9)$ & $0(0.0)$ & $1(2.0)$ & 5.891 & 0.171 \\
\hline Not like that & $8(6.9)$ & $7(10.8)$ & $1(2.0)$ & & \\
\hline So so & $30(25.9)$ & $14(21.5)$ & $16(31.4)$ & & \\
\hline Mostly & $60(14.7)$ & $33(50.8)$ & $27(52.9)$ & & \\
\hline It really & $17(0.9)$ & 11(16.9) & $6(11.8)$ & & \\
\hline \multicolumn{6}{|c|}{ Dementia is linked to genetic factors } \\
\hline Not at all & $1(0.9)$ & $0(0.0)$ & $1(2.0)$ & 7.370 & 0.091 \\
\hline Not like that & $13(11.2)$ & $10(15.4)$ & $3(5.9)$ & & \\
\hline So so & $38(32.8)$ & $25(38.5)$ & $13(25.5)$ & & \\
\hline Mostly & $53(45.7)$ & $24(36.9)$ & $29(56.9)$ & & \\
\hline It really & $11(9.5)$ & $6(9.2)$ & $5(9.8)$ & & \\
\hline \multicolumn{6}{|c|}{ Men are more susceptible to dementia than women. } \\
\hline Not at all & $5(4.3)$ & $5(7.7)$ & $0(0.0)$ & 8.832 & 0.043 \\
\hline Not like that & $53(45.7)$ & $33(50.8)$ & $20(39.2)$ & & \\
\hline So so & 39 (33.6) & $16(24.6)$ & $23(45.1)$ & & \\
\hline Mostly & $18(15.5)$ & $10(15.4)$ & $8(15.7)$ & & \\
\hline It really & $1(0.9)$ & $1(1.5)$ & $0(0.0)$ & & \\
\hline Not at all & $0(0.0)$ & $0(0.0)$ & $0(0.0)$ & & \\
\hline \multicolumn{6}{|c|}{ Stroke can lead to dementia } \\
\hline Not like that & $6(5.2)$ & $5(7.7)$ & $1(2.0)$ & 6.058 & 0.104 \\
\hline So so & 30 (25.9) & $21(32.3)$ & $9(17.6)$ & & \\
\hline Mostly & $57(49.1)$ & 29 (44.6) & $28(54.9)$ & & \\
\hline It really & 23 (19.8) & 10 (15.4) & $13(25.5)$ & & \\
\hline
\end{tabular}


Table 5. Treatment knowledge of dementia

\begin{tabular}{|c|c|c|c|c|c|}
\hline & Total & $\begin{array}{c}\text { Physical } \\
\text { therapist N (\%) }\end{array}$ & $\begin{array}{l}\text { Occupational } \\
\text { therapist N (\%) }\end{array}$ & $\chi^{2}$ & $p$ \\
\hline \multicolumn{6}{|c|}{ Dementia cannot be detected early } \\
\hline Not at all & $4(3.4)$ & $1(1.5)$ & $3(5.9)$ & \multirow[t]{5}{*}{10.446} & \multirow[t]{5}{*}{0.027} \\
\hline Not like that & $18(15.5)$ & $14(21.5)$ & $4(7.8)$ & & \\
\hline So so & $17(14.7)$ & $10(15.40$ & $7(13.7)$ & & \\
\hline Mostly & $55(47.4)$ & $33(50.8)$ & $22(43.1)$ & & \\
\hline It really & $22(19.0)$ & $7(10.8)$ & $15(29.4)$ & & \\
\hline \multicolumn{6}{|c|}{ There are also treatable dementia } \\
\hline Not at all & $2(1.7)$ & $2(3.1)$ & $0(0.0)$ & \multirow[t]{5}{*}{14.884} & \multirow[t]{5}{*}{0.003} \\
\hline Not like that & $17(14.7)$ & $5(7.7)$ & $12(23.5)$ & & \\
\hline So so & 39 (33.6) & $21(32.3)$ & $18(35.3)$ & & \\
\hline Mostly & $45(38.8)$ & $33(50.8)$ & $12(23.5)$ & & \\
\hline It really & $13(11.2)$ & $4(6.2)$ & $9(17.6)$ & & \\
\hline \multicolumn{6}{|c|}{ Cognitive function tests are important to diagnose dementia } \\
\hline Not at all & $1(0.9)$ & $1(1.5)$ & $0(0.0)$ & \multirow[t]{5}{*}{8.384} & \multirow[t]{5}{*}{0.045} \\
\hline Not like that & $3(2.6)$ & $2(3.1)$ & $1(2.0)$ & & \\
\hline So so & $15(12.9)$ & $13(20.0)$ & $2(3.9)$ & & \\
\hline Mostly & $62(53.4)$ & $30(46.2)$ & $32(62.7)$ & & \\
\hline It really & $35(30.2)$ & $19(29.2)$ & $16(31.4)$ & & \\
\hline \multicolumn{6}{|c|}{ There is no way to prevent dementia } \\
\hline Not at all & $1(0.9)$ & $1(1.5)$ & $0(0.0)$ & \multirow[t]{5}{*}{10.028} & \multirow[t]{5}{*}{0.026} \\
\hline Not like that & $11(9.5)$ & $10(15.4)$ & $1(2.0)$ & & \\
\hline So so & $28(24.1)$ & $18(27.7)$ & $10(19.6)$ & & \\
\hline Mostly & $54(46.6)$ & $24(36.9)$ & $30(58.8)$ & & \\
\hline It really & $22(19.0)$ & $12(18.5)$ & $10(19.6)$ & & \\
\hline \multicolumn{6}{|c|}{ Regular exercise lowers your risk of dementia } \\
\hline Not at all & $0(0.0)$ & $0(0.0)$ & $0(0.0)$ & \multirow[t]{5}{*}{4.0588} & \multirow[t]{5}{*}{0.256} \\
\hline Not like that & $3(2.6)$ & $2(3.1)$ & $1(2.0)$ & & \\
\hline So so & $20(17.2)$ & $15(23.1)$ & $5(9.8)$ & & \\
\hline It really & $64(55.2)$ & $34(52.3)$ & $31(58.8)$ & & \\
\hline It really & $29(25.0)$ & $14(21.5)$ & $15(29.4)$ & & \\
\hline \multicolumn{6}{|c|}{ Regular living and regular physical examination help prevent dementia } \\
\hline Not at all & $0(0.0)$ & $0(0.0)$ & $0(0.0)$ & \multirow[t]{5}{*}{6.311} & \multirow[t]{5}{*}{0.072} \\
\hline Not like that & $1(1.5)$ & $1(2.0)$ & $2(1.7)$ & & \\
\hline So so & $14(21.5)$ & $3(5.9)$ & $17(14.7)$ & & \\
\hline Mostly & $30(46.2)$ & $31(60.8)$ & $61(52.6)$ & & \\
\hline It really & $20(30.8)$ & $16(31.4)$ & $36(31.0)$ & & \\
\hline \multicolumn{6}{|c|}{ Physical or occupational therapy can slow the progression of dementia } \\
\hline Not at all & $0(0.0)$ & $0(0.0)$ & $0(0.0)$ & \multirow[t]{5}{*}{12.541} & \multirow[t]{5}{*}{0.005} \\
\hline Not like that & $7(6.0)$ & $5(7.7)$ & $2(3.9)$ & & \\
\hline So so & $31(26.7)$ & $25(38.5)$ & $6(11.8)$ & & \\
\hline Mostly & $48(41.4)$ & $21(32.3)$ & $27(52.9)$ & & \\
\hline It really & $30(25.9)$ & $14(21.5)$ & $16(31.4)$ & & \\
\hline \multicolumn{6}{|c|}{ Drug treatment helps with dementia } \\
\hline Not at all & $0(0.0)$ & $0(0.0)$ & $0(0.0)$ & 6.606 & 0.069 \\
\hline Not like that & $3(2.6)$ & $2(3.1)$ & $1(2.0)$ & & \\
\hline So so & $32(27.6)$ & $23(35.4)$ & $9(17.6)$ & & \\
\hline Mostly & $64(55.2)$ & $34(52.3)$ & $30(58.8)$ & & \\
\hline It really & $17(14.7)$ & $6(9.2)$ & $11(21.6)$ & & \\
\hline
\end{tabular}


Table 5. Continued

\begin{tabular}{|c|c|c|c|c|c|}
\hline & Total & $\begin{array}{c}\text { Physical } \\
\text { therapist N (\%) }\end{array}$ & $\begin{array}{l}\text { Occupational } \\
\text { therapist N (\%) }\end{array}$ & $\chi^{2}$ & $\mathrm{p}$ \\
\hline \multicolumn{6}{|c|}{ Eating lightly and eating well-balanced meals is effective in preventing dementia. } \\
\hline Not at all & $0(0.0)$ & $0(0.0)$ & $0(0.0)$ & 0.738 & 0.919 \\
\hline Not like that & $7(6.0)$ & $4(6.2)$ & $3(5.9)$ & & \\
\hline So so & $30(25.9)$ & $17(26.2)$ & $13(25.5)$ & & \\
\hline It really & $64(55.2)$ & $37(56.9)$ & $27(52.9)$ & & \\
\hline It really & $15(12.9)$ & $7(10.8)$ & $8(15.7)$ & & \\
\hline \multicolumn{6}{|c|}{ Controlling blood pressure or blood sugar helps prevent dementia } \\
\hline Not at all & $0(0.0)$ & $0(0.0)$ & $0(0.0)$ & 1.889 & 0.613 \\
\hline Not like that & $5(4.3)$ & $3(4.6)$ & $2(3.9)$ & & \\
\hline So so & 35 (30.2) & $20(30.8)$ & 15 (29.4) & & \\
\hline Mostly & 57 (49.1) & $29(44.6)$ & 28 (54.9) & & \\
\hline It really & 19 (16.4) & $13(20.0)$ & $6(11.8)$ & & \\
\hline
\end{tabular}

Table 6. Correlation of perception of dementia

\begin{tabular}{|c|c|c|c|c|}
\hline & Awareness & Symptom knowledge & Disease knowledge & Therapy knowledge \\
\hline Awareness & 1 & & & \\
\hline Symptom knowledge & $0.473^{* * *}$ & 1 & & \\
\hline Disease knowledge & $0.631 * * *$ & 0.131 & 1 & \\
\hline Therapy knowledge & $0.878^{* * *}$ & 0.143 & $0.337^{* * *}$ & 1 \\
\hline
\end{tabular}

${ }^{*} p<0.05,{ }^{* *} p<0.01,{ }^{* * *} p<0.001$.

저 물리치료사와작업치료사의 치료대상은 아동과 성인에 비해 노인 이 적었으며, 치매 치료 경험은 비슷한 것으로 나타났다. 또한 치매 인 식도도 차이가 많이 나타나지 않았다. 2021년 통계청에 의하면 물리 치료사와작업치료사의 대학병원, 일반병원 취업자가 만 5 천 명이 넘 는 것으로 집계되었으며 그에 반해 요양병원에 취업한 인원은 만 명 이 조금 넘는 것으로 나타났다. ${ }^{2} \mathrm{Lee}^{23}$ 의 연구에 의하면 요양병원에 입 원한 환자가 고혈압과 치매, 근골격계 질환 등으로 65 세 이상의 노인 환자가 가장 많은 것으로 나타났다. 이는 대부분의 치매 노인은 요양 원이나 요양병원에서 치료를 받기 때문에 치료사가 치매 노인을 만나 고, 치료하는 것이 소아 환자나 성인 환자보다 한정적일 것으로 생각 된다. 또한 치매 치료 경험도 적을 것으로 사료된다. 치매 인식도에 관 한 집단 별 평균과 표준편차는 물리치료사보다 작업치료사의 인식 도가 유의하게 높았으며, 인식도의 세부항목인 증상지식과 질병지식, 치료지식에서 모두 작업치료사가 유의하게 높게 나타났다. Son ${ }^{18}$ 의 연구에서 노인장기요양기관의 관리자와 요양보호사의 치매 인식도 에 유의한 차이를 보이지 않았다. 이는 치매 환자를 위해 국민건강보 험공단에서 실시한 '치매전문교육'을 이수한 영향임을 알 수 있다. '치 매전문교육에는 작업치료사를 위한 교육과정이 있으나 물리치료사 를 위한 교육과정이 없기 때문에 이러한 교육을 받은 작업치료사가 받지 못한 물리치료사보다 인식도가 더 높을 것으로 사료된다.

치매 인식도 중 치매 증상에 관한 지식에서 '나이가 들면 노화에
의해 치매에 걸린다', '치매에 걸리면 가족과 생활하는 것이 불가능하 다, '치매에 걸리면 이전에 비해 기억력 등 인지 기능이 저하되어 일상 생활에 지장을 초래하게 된다, '치매에 걸리면 성격이 변할 수 있다'에 서 유의한 차이가 나타나지 않았다. 그러나 '치매를 위해서는 환경을 자주 바꾸어 주면 도움이 된다'에서는 유의한 차이가 나타났다. '치매 를 위해서 환경에 변화를 주면 안 된다라는 인식이 작업치료사 $80.4 \%$ 로 물리치료사 $60 \%$ 보다 높았다. 작업치료사는 치매지원센터에 서 치매 예방을 위해 치매 예방교실과 치매 가족 상담을 담당하고 있 기 때문에 환경의 변화가 치매 환자에게 좋지 않음을 더 자세히 인식 했을 것이다. ${ }^{24}$

질병에 관한 지식에서 '치매는 병이다', '치매는 음주나 약물과 관련 이 있다', '치매는 유전적인 요인과 관련이 있다', '뇌졸중 때문에 치매 가 생길 수 있다'에서는 집단에 따른 유의한차이가 나타나지 않았다. 그러나 ‘남자가 여자보다 치매에 잘 걸린다’에서는 유의한 차이가 나 타났다. '여자가 남자보다 치매에 잘 걸린다'라는 인식은 물리치료사 가 $58.5 \%$ 로 작업치료사 $39.2 \%$ 보다 높았다. 우리나라는 여성의 치매 유병률이 $7.63 \%$ 로 남성 $5.87 \%$ 보다 높다..$^{25}$ 그러나 헝가리 세게드 의과 대학 연구진은 남자가 여자보다 두뇌 위축 속도가 빨라 치매에 잘 걸 린다는 연구 결과를 내놓았다. ${ }^{26}$ 물리치료사는 우리나라에서 발생되 고 있는 치매 현황을 바라보는 시각에서, 작업치료사는 치매 전체를 바라보는 시각에서의 차이일 것으로 사료된다. 
치료에 관한 지식에서 치매는 조기 발견이 불가능하다', '치료 가능 한 치매도 있다', '치매 진단을 하기 위해 인지 기능검사가 중요하다', '치매는 예방할 수 있는 방법이 없다', '물리치료나작업치료로 치매의 진행을 늦출 수 있다'에서 유의한 차이가 나타났다. '치료 가능한 치 매도 있다'에서는 물리치료사가 $57 \%$, 작업치료사 $41.1 \%$ 보다 높았지만 나머지 4 개의 질문에서는 작업치료사가 높게 나타났다. 그러나 규칙 적으로 운동하면 치매 위험이 낮아진다', 규칙적인 생활과 신체 정기 검사는 치매예방에 도움을 준다, '치매는 약물치료가 도움이 된다', '싱겁게 먹고 균형에 맞는 식사는 치매예방에 효과적이다' '혈압이나 혈당 조절이 치매 예방에 도움이 된다'에서 유의한 차이가 나타나지 않았다. Kwon ${ }^{14}$ 의 연구에 의하면 치매관련 교과목 이수 여부와 실습 경험의 유무에 따라 작업치료사의 치매지식이 유의하게 나타났다. 이는 작업치료사들이 치매 관련한 과목과 경험이 물리치료사들보 다 많고 다양함에 있을 것으로 생각되며, 치매 관련 작업치료와 물리 치료 교육과정의 차이와 실습 경험 유무 등에 대한 추후 연구가 필요 할 것으로 사료된다.

치매 인식도에 관한 상관관계는 증상지식과 질병지식, 치료지식 모두에서 유의한 정적 상관을 나타냈다. 질병지식은 치료지식과의 관계에서 정적 상관이 나타났으나, 증상지식은 질병지식과 치료지식 에서는 상관을 보이지 않았다. 이는 치매 질병에 대한 지식을 제대로 알아야 그에 맞는 적절한 치료를 할 수 있을 것으로 생각되며, 치매에 관련된 질병이나 후유증을 대비할 수 있을 것으로 사료된다.

물리치료사와 작업치료사는 배우는 과목이 조금 다르며, 치매를 대하는 접근 방식이나 치료방식도 다르다. 그러나 언제 어디서든 치 매를 치료하는 의료기사이기 때문에 치매를 위한 고민의 공감대 형 성도 이루고 있을 것이다. 따라서 이 연구를 통해 의료기사로서, 치매 에 같은 관심을 갖는 공동체로서 치매 인식도를 높일 수 있도록 서로 노력하여 치매 치료의 서비스 질을 높여 나가야 할 것이며, 전문가로 서의 영역도 확장시켜 나가야 할 것이다. 또한 치매에 대해 목표를 같 이하고 치매 환자를 위한 치료 방향을 향해 나가는 의료기사들이 함 께 고민할 수 있는 다양한 교육과 시스템의 방안이 마련되어야 할 것 이다.

본 연구의 제한점은 물리치료사와 작업치료사가 전국적으로 5 만 명이 넘는데 반해 설문 조사에 응한 인원은 $0.22 \%$ 밖에 되지 않아서 전체 의료기사(물리, 작업치료사)의 치매 인식도라고 단정 지을 수 없 으며, 의료기사의 치매 인식도에 관한 문헌 자료가 부족하여 직접 비 교, 분석할 수 없다는 것이다. ${ }^{2}$

\section{REFERENCES}

1. Seoul citizens' dementia awareness survey report [Internet]. South Ko- rea: 2018 Nov [cited 2021 Feb 16]. Available from: www.seouldementia. or.kr.

2. Statistical Office. National Statistical Portal (KOSIS) Statistical Table [Internet]. South Korea: 2021. [cited 2021 May 6]. Available from: www.kostat.go.kr.

3. Kim WJ, Jung ES. Comparison of dementia awareness of local people by residential area: focusing on gyeonggi-do region in 2017. J KALCI. 2018; 18(21):123-38.

4. Central Dementia Center [Internet]. South Korea: 2021 Feb [cited 2021 Feb 25]. Available from: www.nid.or.kr.

5. Park SY, Kim DJ. The effect of the visit to dementia home experience program on the awareness of dementia. J KAIS. 2018;19(10):263-71.

6. Lee EJ, Jo MK. A study on perception of and attitude toward dementia and depression of residents in a community. J East-West Nurs Res. 2017; 23(2):180-9.

7. Dementia exercise program for physical therapists. Type of dementia [Internet]. South Korea: 2019 Oct [cited 2021 May 8]. Available from: www.kspta.or.kr.

8. Yang SK, Park JH. Exploring the possibility of using early childhood education contents in the elderly dementia prevention program. J KAIS. 2020;21(8):495-500.

9. Kim ChM, Kim JH. The effect of the dementia elderly persons on the cognitive function, ADL and balance-performing ability the group therapeutic exercise program. J Phys Ther Sci. 2012;19(4):27-34.

10. Lee IS, Lee GH, Kim SJ et al. The effects of exercise programs on gait ability of elderly dementia patients. J Kor Phys Ther. 2001;13(3):551-9.

11. Son HH, Oh JL, Park RJ. The effect of an exercise program on activities of daily living (ADL), balance and cognition in elderly individuals with Alzheimer's disease and vascular dementia. J Kor Phys Ther. 2010; 22(1):43-60.

12. Medical Technician Act, Act on Medical Technicians, etc. Article 1-2, Article 2 [Internet]. South Korea: 2020 Dec [cited 2021 May 9]. Available from: www.law.go.kr.

13. Medical Technician Act, Medical Technician Act, Article 2 [Internet]. South Korea: 2020 Dec [cited 2021 May 9]. Available from: www.law. go.kr.

14. Kwon MH. Effects of dementia-related experiences on dementia awareness and career hopes of occupational therapy majors. Korea J Occup Ther. 2019;27(4):83-91.

14. Song YS, Bae NK, Jo YC. Age-related physical function (ADL, IADL) and its related factors of elderly people in Korea. J KAIS. 2015;16(3): 2002-11.

16. Cho YK. The distribution of medical technologists in Korea. Journal of Health and Medical Science. 2015;4(1):37-46.

17. Kim YS, Cho WS. A study on the perception of dementia by students of physical therapy Ggangju and Jeonnam. J Phys Ther Sci. 2018;25(3):4352.

18. Son SJ. A study on awareness and attitudes of dementia in long-term care facilities workers. J KALCI. 2019;19(22):1297-313.

19. Lam Freddy MH, Huang MZ, Liao LR et al. Physical exercise improves strength, balance, mobility, and endurance in people with cognitive impairment and dementia: a systematic review. J Physiother. 2018;64(1);415.

20. Tim F, Hannah D, Marleen G et al. Structured physical exercise improves 
neuropsychiatric symptoms in acute dementia care: a hospital-based RCT. Alzheimer's Res Ther. 2017;9(68):1-9.

21. Han MI, Kim KM, Oh JY et al. A rural dementia-friendly village project and dementia awareness, cognition, and depressive symptom : a preliminary study. J Korean Geriatr Psychiatry. 2018;22(1):13-8.

22. Kim KS. A study on the Jeju citizens' awareness and attitude on dementia. Jeju University. Dissertation of Master's Degree. 2012.

23. Lee SK. An analysis on the Use of Hospitalization for the elderly aged 65 or older in Yeongbuk, Gangwon-do. JHCLS. 2021;9(1):95-102.
24. Hong SY. The survey on the awareness, interest and need of occupational therapy students for the dementia care center. The Journal of Korean Society of Community Based Occupational Therapy. 2018;8(3):37-47.

25. Park SH, Lee YW, Lim DO. Dementia mortality among aged 60 years and older in Korea: 2014-2018. Korean Public Health Research. 2020; 46(4):107-15.

26. Oedekoven CS, Jansen A, Keidel JL et al. The influence of age and mild cognitive impairment on associative memory performance and underlying brain networks. Brain Imaging Behav. 2015;9(4):776-89. 